\title{
Hoof Discomfort Changes How Dairy Cattle Distribute Their Body Weight
}

\author{
S. Neveux, ${ }^{*} \dagger$ D. M. Weary, ${ }^{*}$ J. Rushen, ${ }^{*}{ }^{1}$ M. A. G. von Keyserlingk, ${ }^{*}$ and A. M. de Passillé ${ }^{\star} \dagger$ \\ *Animal Welfare Program, University of British Columbia, 2357 Main Mall, Vancouver, British Columbia, V6T 1Z4, Canada \\ †Agriculture and Agri-Food Canada, PO Box 1000, Agassiz, British Columbia, VOM 1A0, Canada
}

\section{ABSTRACT}

Lameness is a costly and widespread health and welfare problem in intensive dairy production, and reliable automated methods to detect lameness are needed. Lameness may be detected through the measurement of how cattle distribute their weight among their 4 legs, but this requires an understanding of how cattle redistribute their weight in response to pain in one or more limbs. In 3 experiments, 13, 12, and 15 Holstein dairy cows were trained to stand on a platform that measured the weight placed on each limb. We replaced the soft rubber surface under either 1 or 2 hooves with an uncomfortable concrete surface. Cows placed less weight on a back hoof that was placed on an uncomfortable surface, and they redistributed the majority of the weight onto the contralateral back hoof but did not change the distribution of weight on their front hooves. When the same surface was placed under a front hoof, cows placed less weight on that hoof and placed more weight on the contralateral front hoof and the ipsilateral back hoof. The variation in weight the cow placed on both contralateral hooves increased when one of the hooves was on the uncomfortable surface. Cows placed more weight on the back hooves when both front hooves were standing on uncomfortable surfaces, although no change was observed when back hooves were on uncomfortable surfaces. Dairy cows remove weight from a limb in response to limb discomfort and redistribute this weight primarily to the contralateral limb. The variation in weight over time applied to a pair of contralateral limbs increases in response to discomfort in one hoof. Cows have only limited ability to shift weight from front to back. Measures of weight distribution may provide useful on-farm techniques for the detection of lameness.

Key words: dairy cow, lameness, weight distribution, welfare

\section{INTRODUCTION}

Lameness is a costly and widespread health and welfare problem in intensive dairy production. Economic

Received September 26, 2005.

Accepted January 24, 2006.

${ }^{1}$ Corresponding author: rushenj@agr.gc.ca losses associated with lameness include decreased milk production, weight loss, reduced fertility, treatment costs, and involuntary culling (e.g., Green et al., 2002; Hernandez et al., 2002; Booth et al., 2004; Garbarino et al., 2004). Early detection and treatment of lameness is essential to reduce its prevalence and economic costs (Clarkson et al., 1996; Nordlund et al., 2004), but research has shown that, on average, dairy producers are aware of only 25 to $50 \%$ of the cows that are lame (Wells et al., 1993; Whay et al., 2003). Lameness in dairy cattle is normally assessed using subjective gait scoring systems (e.g., Manson and Leaver, 1988; Sprecher et al., 1997), which provide an easy and inexpensive method of detecting hoof lesions (Winckler and Willen, 2001; Colborne, 2004; Flower and Weary, 2006). However, the increasing size of dairy farms and the limited amount of time available to dairy producers to observe cows has led to an interest in automated means of detecting lameness (e.g., Rajkondawar et al., 2002).

In horses, lameness has been studied by measuring the load applied to each limb (e.g., Keegan et al., 1998; Hood et al., 2001). When animals are lame, relief may be gained by reducing the weight loaded on the painful limb by transferring weight to the other limbs (Gahéry and Nieoullon, 1978; Coulmance et al., 1979). In addition to these changes in limb loading, animals may also respond to discomfort by repeatedly shifting weight among their limbs (Hood et al., 2001). Thus, both the magnitude and variability in weight applied to a limb may be used as a measure of pain associated with lameness (Rietmann et al., 2004).

Rajkondawar et al. (2002) described how lame cows could be identified successfully by the loads applied to individual limbs when walking. However, under some circumstances, a force platform measuring weight distribution among limbs when cows are standing may be easier to implement on farms. Neveux et al. (2003) presented preliminary correlational data showing that cows with hoof lesions showed a greater variability in weight distribution among the 4 limbs when standing, compared with healthy cows. However, there was no direct relationship between the presence of visible injuries on a hoof and the weight placed on that limb. One limitation to this approach is that few cows can be clearly identified as having lesions on only one hoof. 
To refine the use of measures of weight distribution to detect lameness, we need to know how cows redistribute their weight among their remaining limbs in response to discomfort in one or more limbs. Thus, the objectives of the current study were to evaluate how nonlame cows distribute their weight while standing and how they change both the magnitude and variability in limb loading in response to hoof discomfort in both a single hoof and a pair of contralateral (i.e., opposite side of the body) hooves.

\section{MATERIALS AND METHODS}

In 3 experiments, we used standing surfaces that we judged to be either comfortable or uncomfortable for the cow to stand on, and we measured how cows that were not lame changed their weight distribution when one or a pair of hooves were on an uncomfortable surface.

\section{Animals and Housing}

In experiment 1 , we used 13 Holstein dairy cows (mean $\pm \mathrm{SD}$; parity of $1.2 \pm 0.6$; BW $636 \pm 75 \mathrm{~kg}$ ). Two of the cows were not lactating and the remaining 11 averaged $260 \pm 94 \mathrm{~d}$ in milk (DIM). For experiment 2 , we used 12 Holstein dairy cows, and in experiment 3 , we used 15 lactating Holstein dairy cows (parity $1.2 \pm$ 0.4 ; BW $617 \pm 61 \mathrm{~kg}$; DIM $208 \pm 62$ ). All cows were housed in a tie-stall barn at Agriculture and Agri-Food Canada's research station in Lennoxville, Quebec.

We selected cows that were not lame using measures of gait and hoof health from 4 monthly hoof evaluations and gait scoring sessions. To assess hoof health, animals were restrained in a horizontal-trimming chute operated by a professional hoof trimmer. The hoof trimmer pared approximately $1 \mathrm{~mm}$ of the sole horn from the hoof, and the presence and severity of injuries (hemorrhage of the wall, hemorrhage of the sole, sole ulcer, dermatitis, and heel erosion) was recorded for all hooves (Table 1). All cows were correctively trimmed 1 mo before the start of the study and again at the end of the experiment. During each gait scoring session, a handler walked behind the cows, encouraging them to walk in a consistent manner along a $13-\mathrm{m}$-long by $1.3-\mathrm{m}$-wide nongrooved concrete passageway. Each cow was videotaped from her right side. The video camera was placed $6 \mathrm{~m}$ from the cow, which allowed us to record at least 4 complete strides for each cow during each passage. A second video camera was mounted $1.8 \mathrm{~m}$ above the floor, pointed toward the rear of the cow, to allow for scoring of abduction and adduction of the back limbs. An experienced observer used these videos to assign each cow a gait score on the 5-point scale described by Flower and Weary (2006). The gait scoring system requires that the scorers rate the cow on a scale for several components of gait that change as cows become lame. These components are the degree of tracking up (i.e., the extent that the back hoof is placed in the same place as the front hoof), head bobbing, arched back, swinging out, asymmetric steps, joint flexion, and reluctance to bear weight. Based on these ratings, each cow is given an overall numerical rating score, which ranges from 1 (perfect gait) to 5 (severely lame). Generally, a score of 3.0 is considered as the cutoff for classifying a cow as lame, and in this experiment we included cows only if the gait score was less than 3 in the scoring session conducted immediately prior to the experiment.

In experiment 1, 24 cows were originally tested. Eight cows were removed because of the presence of hoof lesions ( 4 with ulcers, 2 with sole hemorrhages, 1 each with digital dermatitis and granuloma). In experiment 3 , of the 16 cows originally tested, 1 was removed because of lameness, as indicated by her gait score $(>3.0)$ and hoof health evaluation, which identified an ulcer on the right back hoof.

The cows retained in experiments 1,2 , and 3 had average gait scores ( \pm SD) of $2.69 \pm 0.60,2.12 \pm 0.61$, and $2.03 \pm 0.63$, respectively.

\section{Load Cells and Platform}

The weight distribution of cows was measured while they were standing on a platform containing 4 independent recording units (each $56 \times 91 \mathrm{~cm}$ ) fitted in a $1.9 \times$ $1.3 \mathrm{~m}$ enclosure. Each recording unit contained 2 singlepoint load cells (Vishay Tedea-Huntleigh model 1250; Vishay, Selb, Germany). The load cells were mounted off-center at either end of each unit. Within each load cell, the internal strain gauges measured deformation from the tension and compression proportional to the vertical load applied. Horizontal forces were not measured. The corresponding change in electrical resistance was transmitted via an electrical signal to the acquisition hardware FieldPoint (National Instruments, Austin, TX) at a rate of one reading every $0.9 \mathrm{~s}$ for experiment 1 and every $0.25 \mathrm{~s}$ for experiments 2 and 3 . The load cells were calibrated periodically during the study using dead-weight calibration with standard weights. The weights recorded were always the same regardless of the position on the unit. LabView (Version 8; National Instruments) was used to provide a realtime graphical display of the weight applied to each of the 4 units, and data were automatically stored on a computer.

In experiment 1 , the platform stood $16 \mathrm{~cm}$ above the floor and had a $2.3-\mathrm{m}$ entrance and exit ramp (sloped approximately $4^{\circ}$ from the floor) at the front and back 
Table 1. Hoof health evaluation ${ }^{1}$

\begin{tabular}{lll}
\hline \multirow{2}{*}{ Injury } & Severity & \\
\hline Dermatitis & score & Description \\
& 0 & No dermatitis \\
& 1 & Light dermatitis \\
Heel erosion & 2 & Moderate dermatitis \\
& 3 & Severe dermatitis; dermis is exposed \\
& 0 & No heel erosion \\
Hemorrhage of the sole or white line & 2 & Light heel erosion \\
& 3 & Moderate heel erosion \\
& 1 & Severe heel erosion; dermis is exposed \\
& 2 & No hemorrhage \\
Ulcer & 3 & Light hemorrhage; petechia or localized hemorrhage, with altered coloration \\
& & Covering less than 10\% of the sole or the white line \\
& 0 & Severe hemorrhage, covering more than $25 \%$ of the sole or the white line, or \\
& 1 & coloring a localized region with a deep red \\
& 2 & No ulcer \\
& 3 & Insult to the sole exposing the dermis \\
\hline
\end{tabular}

${ }^{1}$ Adapted from Manske et al. (2002).

of the enclosure. The side barriers of the platform were $2.1 \mathrm{~m}$ high and were made of 6 lateral steel bars. An adjustable rear barrier discouraged cows from reversing and allowed handlers to correct the position of the cows safely. An 81-cm-tall door made of solid wood, with a 37-cm-wide opening for the cow's head, prevented the animal from moving forward while in the enclosure. Observations of cows during preliminary trials showed that head movement influenced the weight distribution. Therefore, to limit the cow's peripheral view and ability to move her head, the door was equipped with lateral blinders that extended $19 \mathrm{~cm}$ from the door.

Individual limb and head positions of the cows while standing on the platform were recorded using 2 video cameras. These recordings were monitored to ensure that hooves were correctly placed on the platform throughout the period in which loads were measured. If a hoof was not placed on the correct load-recording unit, the cow was gently manipulated to encourage repositioning. The timing of each of these manipulations was identified using the video recordings, and $10 \mathrm{~s}$ of the load data before and after each event were eliminated from the analysis. The first and last $30 \mathrm{~s}$ of each session on the platform were also removed to account for cows adjusting their position while entering and exiting the platform.

The materials and procedures just described were identical in experiments 2 and 3, with the following exceptions: The lateral barriers on the platform were placed closer to the cows to improve the likelihood that the cows correctly placed their hooves on the recording units. Because of the improved procedures present in experiment 2 , we removed only $5 \mathrm{~s}$ of the load data before and after manipulations to correct for cow positioning on the platform.

\section{Standing Materials}

In all experiments we used a comfortable flooring surface of 3.8-cm-thick revulcanized rubber mats (Animat, Saint-Élie d'Orford, Quebec), and an uncomfortable concrete surface, which was intended to cause mild discomfort but not injure the animals. In experiment 1 , we created an uncomfortable standing surface by placing rocks in the standing surface. Rocks were approximately $1.3 \mathrm{~cm}$ thick and were placed directly into the concrete at the time of manufacturing. The rocks ( 5 per $15 \mathrm{~cm}^{2}$ ) protruded $0.6 \mathrm{~cm}$ above the surface of the concrete. Difficulties associated with the inconsistent size and placement of the rocks created spatial variation within and among the units. Thus, to create a more uniform surface in experiments 2 and 3 , we used screw heads, which we were able to place in a very consistent manner within the standing surface. These screw heads were placed at 5 per $15 \mathrm{~cm}^{2}$, had smooth concave surfaces $1.8 \mathrm{~cm}$ in diameter, and protruded 2.0 $\mathrm{cm}$ above the concrete surface. In all experiments, we followed the hoof health and gait of the cows to ensure that the treatments did not cause any injury or evidence of longer-term pain. We also gait scored the cows at the beginning and the end of their respective test days and detected no changes in locomotion.

\section{Experimental Procedures}

In experiment 1 , we placed the uncomfortable surface under either a single front or back hoof. The cows were 
walked along a passageway and stood on the platform in a calm and manageable manner. Each cow received each of 3 treatments, presented in a balanced order across cows: 1 ) all 4 surfaces were rubber (control); 2 ) the right back surface was concrete embedded with rocks and the other 3 surfaces were rubber (right back, RB); and 3) the right front surface was concrete embedded with rocks and the other 3 surfaces were rubber (right front, RF). Cows stood on the platform for approximately 5 min during each test and were returned to their stalls between tests. Because of time limitations, we evaluated weight distribution changes in response to discomfort on the right side only. Treatments were imposed once per cow at 1-h intervals, and recordings were started immediately after the morning milking. The 3 treatments for each cow were completed during a single day.

In experiment 2 we tested the effectiveness of our alternative uncomfortable standing surface by using screws rather than embedded rocks. The experimental procedure was identical to that of experiment 1 , except that cows stood on the platform for 2 min to minimize the risk of injury.

In experiment 3 , we placed uncomfortable surfaces under both front hooves or both back hooves. The cows were walked along the passageway and stood on the platform in a calm and manageable manner. Each cow received each of the 3 treatments: 1) all 4 surfaces were rubber (control); 2) both front units had concrete surfaces embedded with screws and both back units had rubber surfaces (front pair); and 3) both back units had concrete surfaces embedded with screws and both front units had rubber surfaces (back pair). To minimize the risk of injury while standing on the uncomfortable units, cows stood for only 2 min before being returned to their stalls. The 2 uncomfortable surface treatments were presented in a balanced order across cows, between 2 repetitions of the control condition. Treatments were imposed once for each cow at 30-min intervals, and all treatments for each cow were completed in a single day.

\section{Statistical Analysis}

Of the 16 cows originally tested in experiment 1 , the data from 3 cows could not be used because of technical difficulties with the platform. Five of the remaining 13 cows tested were found to have one or more hoof injuries at the completion of the study even though no hoof injuries were visible when the experiment began. However, these cows did not show any overt signs of lameness when walking (gait scores $<3.0$ ) or reluctance to bear weight on the limb while on the platform during the control treatment, and their data were retained for the analysis. Subsequent comparisons of the animals with and without injuries indicated no differences; therefore, the data were pooled prior to the final analyses. The treatments were reasonably balanced among the retained cows.

In experiment 1, PROC MIXED (SAS Institute, 1985), with a model that included cow as a random factor and treatment (control, RB, or RF) as a factor with specified contrasts, was used to test differences in weight applied to all 4 hooves in response to the treatments. We predicted that less weight would be applied to the hooves on the uncomfortable surface and that this weight would be redistributed among the 3 other hooves. In addition, we used the average SD of the load on each limb during the 5-min period for a particular treatment, averaged over of all cows, as the measure of limb-load variation. We predicted that variation in the weight placed on each hoof would increase when the cows were standing on the uncomfortable surface. Analyses for experiment 2 were as described in experiment 1 . For experiment 3 , no differences were found in the weight distribution between the 2 control treatments, so an average of the 2 was used. Analyses were as described in experiment 1 . We predicted that cows would remove weight from the uncomfortable surfaces and increase the variation in weight loading when standing on these surfaces. Load differences on pairs of hooves (front vs. back and left vs. right) during control treatments were tested using matched-pairs $t$-tests.

Data on the proportion of weight applied to each limb were subjected to an arcsine transformation, whereas data on the variability in weight over time were subjected to a square root transformation. However, a similar pattern of significance was obtained with both transformed and untransformed data.

\section{RESULTS}

The results of experiment 1 are shown in Tables 2 and 3 . The proportion of weight (Table 2) placed on the right back hoof during the RB treatment was lower than during the control treatment. The weight placed on the left back hoof increased, but no significant changes were observed in weight placed on the front hooves. During the RF treatment, the animals placed less weight on the right front hoof and more weight on the left front hoof than during control treatments. Cows also increased the weight placed on the right back hoof, but the change in weight applied to the left back hoof was not significant. The presence of an uncomfortable surface under one hoof also changed the variability in weight distribution over time. The variation in weight (Table 3) applied to the back hooves increased by more than 50\% during the RB treatment and by more than 
Table 2. Mean ( $+\mathrm{SE}$ ) percentage of weight distributed on each limb for 3 treatments in experiment 1: 1) control, 2) uncomfortable rock surface placed on the right back unit (RB), and 3) uncomfortable rock surface placed on the right front unit $(\mathrm{RF})$

\begin{tabular}{lllll}
\hline & \multicolumn{3}{c}{ Treatment } \\
\cline { 2 - 4 } Limb & Control & $\mathrm{RB}$ & $\mathrm{RF}$ & SE \\
\hline Right front & $29.4^{\mathrm{a}}$ & $29.7^{\mathrm{a}}$ & $21.2^{\mathrm{b}}$ & 1.0 \\
Left front & $26.0^{\mathrm{a}}$ & $26.7^{\mathrm{a}}$ & $33.6^{\mathrm{b}}$ & 0.9 \\
Right back & $23.5^{\mathrm{a}, \mathrm{x}}$ & $17.8^{\mathrm{b}}$ & $25.2^{\mathrm{a}, \mathrm{y}}$ & 0.7 \\
Left back & $22.5^{\mathrm{a}}$ & $27.6^{\mathrm{b}}$ & $21.3^{\mathrm{a}}$ & 0.6 \\
\hline
\end{tabular}

${ }^{\mathrm{a}, \mathrm{b}}$ Columns with different superscripts differ significantly $(P<$ 0.001).

${ }^{\mathrm{x}, \mathrm{y}}$ Columns with different superscripts differ significantly $(P \leq 0.05)$.

$100 \%$ for the front hooves during the RF treatment. During control sessions in experiment 1, cows placed more weight on the front hooves than on the back hooves ( 54.7 vs. $45.3 \pm 0.4 \% ; t=36.2, \mathrm{df}=12, P<0.001$ ). Cows also distributed more weight on their right side than on their left side (52.0 vs. $48.0 \pm 1.7 \% ; t=2.4$, $\mathrm{df}=12$, $P=0.04$ ).

The results of experiment 2 are shown in Table 4 . The proportion of weight placed on the right back hoof during the RB treatment was lower than during the control treatment, and the weight placed on the left back hoof increased. During the RF treatment, the animals placed less weight on the right front hoof and more weight on the left front hoof than during the control treatments. No significant changes were observed in the weight placed on the back hooves.

The results of experiment 3 are shown in Tables 5 and 6 . The proportion of weight (Table 5) placed on the front hooves decreased by $1.2 \%$ when the uncomfortable surfaces were placed under the front hooves. However, we found no significant effect on weight distribution when the uncomfortable units were under the back hooves. We found no effect of either treatment on the variation in weight applied to the back hooves (Table 6). However, the variation in weight applied to the front hooves was greater when the uncomfortable surface was under the front limbs compared with when the

Table 3. Mean (+ SE) variation of weight distributed on each limb for 3 treatments in experiment 1: 1) control, 2) uncomfortable rock surface placed on the right back unit (RB), and 3) uncomfortable rock surface placed on the right front unit (RF)

\begin{tabular}{|c|c|c|c|c|}
\hline \multirow[b]{2}{*}{ Limb } & \multicolumn{3}{|c|}{ Treatment } & \multirow[b]{2}{*}{$\mathrm{SE}$} \\
\hline & Control & $\mathrm{RB}$ & $\mathrm{RF}$ & \\
\hline Right front & $11.2^{\mathrm{a}}$ & $18.1^{\mathrm{a}}$ & $23.8^{\mathrm{b}}$ & 2.5 \\
\hline Left front & $11.3^{\mathrm{a}}$ & $17.4^{\mathrm{a}}$ & $21.1^{\mathrm{b}}$ & 2 \\
\hline Right back & $15.4^{\mathrm{a}}$ & $27.2^{\mathrm{b}}$ & $17.3^{\mathrm{a}}$ & 2.2 \\
\hline Left back & $16.0^{\mathrm{a}}$ & $24.6^{\mathrm{b}}$ & $16.0^{\mathrm{a}}$ & 2.0 \\
\hline
\end{tabular}

${ }^{\mathrm{a}, \mathrm{b}}$ Columns with different superscripts differ significantly $(P<0.01)$.
Table 4. Mean (+ SE) percentage of weight distributed on each limb for 3 treatments in experiment 2: 1) control, 2) uncomfortable screw surface placed on the right back unit (RB), and 3) uncomfortable screw surface placed on the right front unit $(\mathrm{RF})$

\begin{tabular}{lllll}
\hline & \multicolumn{3}{c}{ Treatment } \\
\cline { 2 - 4 } Limb & Control & $\mathrm{RB}$ & $\mathrm{RF}$ & $\mathrm{SE}$ \\
\hline Right front & $27.7^{\mathrm{a}}$ & $27.3^{\mathrm{a}}$ & $21.5^{\mathrm{b}}$ & 5.4 \\
Left front & $26.3^{\mathrm{a}}$ & $27.5^{\mathrm{a}}$ & $31.7^{\mathrm{b}}$ & 4.7 \\
Right back & $24.2^{\mathrm{a}}$ & $19.7^{\mathrm{b}}$ & $24.2^{\mathrm{a}}$ & 2.0 \\
Left back & $21.7^{\mathrm{a}}$ & $25.5^{\mathrm{b}}$ & $22.6^{\mathrm{a}}$ & 2.7 \\
\hline
\end{tabular}

${ }^{\mathrm{a}, \mathrm{b}}$ Columns with different superscripts differ significantly $(P<0.01)$.

uncomfortable surface was under the back limbs, although neither treatment differed significantly from the control. Cows again placed more weight on the front than on the back hooves (54.0 vs. $46.0 \pm 0.5 \%$; $t=15.7$, $\mathrm{df}=14, P<0.0001$ ) during control sessions. Cows also showed a lateral difference in weight distribution, again placing more weight on the right side than on the left (52.4 vs. $47.6 \pm 1.7 \% ; t=2.8$, df $=14, P=0.013$ ).

\section{DISCUSSION}

Strong reciprocal relationships were found between the degree of load applied to contralateral hooves: When a single hoof was on an uncomfortable surface, the weight removed from this hoof was transferred primarily to the contralateral hoof. This supports the preliminary findings of Neveux et al. (2004), who found strong negative correlations between the amounts of weight applied to contralateral hooves, and also supports the proposal that asymmetric weight distribution within a pair of limbs may indicate lameness (Rajkondawar et al., 2002). Similar contralateral shifts in weight have been observed in dogs (Brookhart et al., 1965; Jevens et al., 1996) and cats (Dufossé et al., 1982; Di Fabio, 1983), and a shifting of weight between contralateral limbs may increase the risk of secondary hoof injuries (Hood et al., 2001).

Table 5. Mean (+ SE) percentage of weight distributed on the front and back limbs for 3 treatments in experiment 3: 1) control, 2) uncomfortable surface placed on the front units, and 3) uncomfortable surface placed on the back units

\begin{tabular}{lllll}
\hline & \multicolumn{3}{c}{ Treatment } \\
\cline { 2 - 4 } & Control & $\begin{array}{l}\text { Front } \\
\text { pair }\end{array}$ & $\begin{array}{l}\text { Back } \\
\text { pair }\end{array}$ & SE \\
\hline Front & $54.0^{\mathrm{a}}$ & $52.8^{\mathrm{b}}$ & $54.4^{\mathrm{a}}$ & 1.0 \\
Back & $46.0^{\mathrm{a}}$ & $47.2^{\mathrm{b}}$ & $45.6^{\mathrm{a}}$ & 1.0 \\
\hline
\end{tabular}

${ }^{\mathrm{a}, \mathrm{b}}$ Columns with different superscripts differ significantly $(P<$ $0.001)$. 
Table 6. Mean (+ SE) variation of weight (measured as the SD of the proportion of weight load) distributed on each limb for 3 treatments in experiment 3: 1) control, 2) uncomfortable surface placed on the front units, and 3) uncomfortable surface placed on the back units

\begin{tabular}{lllll}
\hline & \multicolumn{3}{c}{ Treatment } \\
\cline { 2 - 4 } & Control & $\begin{array}{l}\text { Front } \\
\text { pair }\end{array}$ & $\begin{array}{l}\text { Back } \\
\text { pair }\end{array}$ & SE \\
\hline Front & $30.7^{\mathrm{xy}}$ & $38.8^{\mathrm{x}}$ & $26.4^{\mathrm{y}}$ & 4.8 \\
Back & 34.5 & 33.3 & 35.4 & 5.0 \\
\hline
\end{tabular}

${ }^{\mathrm{x}, \mathrm{y}}$ Columns with different superscripts differ significantly; $P \leq 0.05$.

In experiments 1 and 2 , cows standing with their back hoof on an uncomfortable surface responded by shifting their weight to the contralateral back hoof. No weight was shifted to the front hooves. When the uncomfortable surface was placed under the front hoof in experiment 1 , cows responded by shifting the majority of the weight to the contralateral front hoof. However, some weight was also shifted to the ipsilateral (i.e., same side of the body) back limb. In experiment 2 , which essentially replicated experiment 1 with a different standing surface, we found no evidence that weight was shifted to the ipsilateral back leg. We cannot explain the differences between the 2 experiments, but together the results of experiments 1 and 2 suggest that cows had difficulty shifting their weight from the back limbs to the front limbs, although under some circumstances, some weight could be shifted from front to back. The results found in experiment 3 support this. When the 2 front hooves were on uncomfortable surfaces, the cows proved able to transfer some weight from the front to the back hooves. However, the reverse did not occur when the 2 back hooves were on uncomfortable surfaces. This difference may help explain the higher incidence and recurrent nature of back limb injuries (Greenough and Vermunt, 1991; Clarkson et al., 1996).

The variability over time of the load applied to each limb measured the extent that cows repeatedly shifted their weight while on the platform. Such shifting has previously been suggested to serve as an indicator of lameness (Hood et al., 2001), and Neveux et al. (2003) presented preliminary data showing that lame cows applied a greater variability in load to their hooves. The results of this experiment showed that variation in loads applied to contralateral limbs increased when cows were standing with one hoof on an uncomfortable surface. In experiment 1 , this was true both when the front limb and when the back limb were on an uncomfortable standing surface. Similar results were found by Hood et al. (2001), who reported that horses afflicted with acute laminitis in one limb shifted weight between the contralateral limbs. These results suggest that an increase in weight shifting between contralateral limbs may be used as an indicator of single-limb lameness.

This increased variability in load applied to limbs was less evident when both contralateral hooves were on an uncomfortable surface. We found some slight evidence of an increase in weight shifting in the front limbs when both front hooves were on an uncomfortable surface (compared with when both back hooves were on an uncomfortable surface). However, when both contralateral back limbs were affected, it appeared that cows may not have been able to perform similar weightshifting behavior.

Because our purpose was to examine how cows redistributed their weight when feeling discomfort in one or more hooves, we limited our experiment to nonlame animals. However, at the end of the experiment 1 , we noted that 5 cows had developed hoof lesions either during the course of the experiment or after the experiment had ended. These cows did not show obvious differences in weight distribution during the experiment, suggesting that our weighing scale may have had only limited ability to predict lameness. However, these injuries were insufficient to influence the gait of the cows and so may not have been painful enough to influence weight distribution. Nevertheless, the sample size was too small to draw firm conclusions.

The cows used in experiments 1 and 3 placed more weight on their front hooves than on their back hooves, results supporting previous findings in cattle (55 to $60 \%$ front; 45 to $40 \%$ back; Phillips, 2002) and other quadrupedal mammals (e.g., Budsberg et al., 1987; Hood et al., 2001). However, the proportion of weight applied to the front and back legs was likely to have been affected by the amount of milk in the udder, and in this experiment we were unable to vary the time since milking. In both experiments 1 and 3, we found that cows placed more weight on the right limbs. This difference may have been due to the design of our platform. Even though we had attempted to restrict the cows' movement, they had enough space to move their heads and shift their bodies off center. The off-center location of the rumen may also have influenced weight distribution.

\section{CONCLUSIONS}

Cows standing with discomfort in one hoof remove weight from that hoof and shift it primarily to the contralateral hoof. Furthermore, there is a greater shifting of weight over time between contralateral hooves. Therefore, cows that are lame in one limb would be expected to show a greater asymmetry in weight and a greater variation over time in weight applied to a pair of limbs. Cows that are lame in both front limbs would 
be expected to shift some weight to the back limbs, but lameness affecting both back limbs might not be apparent in changes in weight distribution. Valid, automated methods of detecting lameness in dairy cattle should help improve the identification of lame cows. However, further development of this technique requires that we understand how weight distribution is affected by factors such as time since milking or feeding and how well measures of weight distribution when standing can detect the presence of various hoof injuries. The implementation of such on-farm tools has considerable potential for treating and preventing lameness among cows in the dairy industry, but this method requires further validation.

\section{ACKNOWLEDGMENTS}

S. Neveux was supported by a Natural Sciences and Engineering Research Council of Canada (NSERC) Graduate Scholarship and a University of British Columbia Graduate Fellowship. The research was supported through an NSERC Discovery Grant awarded to A. M. de Passillé. We thank Isabelle Blanchet, Fernando Borderas, Nicole Godin, Daniel Massé, Marjolaine St-Louis, Gosia Zdanowicz, and the staff of the dairy center at the Agriculture and Agri-Food CanadaDairy and Swine Research Centre in Lennoxville, Quebec, for their help in running the experiments, and we thank Nadia Champagne and Jerry Dumont, engineering students from the University of Sherbrooke, for designing and developing the platform.

\section{REFERENCES}

Booth, C. J., L. D. Warnick, Y. T. Grohn, D. O. Maizon, C. L. Guard, and D. Janssen. 2004. Effect of lameness on culling in dairy cows. J. Dairy Sci. 87:4115-4122.

Brookhart, J. M., P. L. Parmeggiani, W. A. Petersen, and S. A. Stone. 1965. Postural stability in the dog. Am. J. Physiol. 208:1047-1057.

Budsberg, S. C., M. C. Verstraete, and R. W. Soutas-Little. 1987. Force plate analysis of the walking gait in healthy dogs. Am. J. Vet. Res. 48:915-918.

Clarkson, M. J., D. Y. Downham, W. B. Faull, J. W. Hughes, F. J. Manson, J. B. Merritt, R. D. Murray, W. B. Russell, J. E. Sutherst, and W. R. Ward. 1996. Incidence and prevalence of lameness in dairy cattle. Vet. Rec. 138:563-567.

Colborne, G. R. 2004. Gait analysis: Technology looking for a place to happen? Vet. J. 168:112-113.

Coulmance, M., Y. Gahery, J. Massion, and J. E. Swett. 1979. The placing reaction in the standing cat: A model for the study of posture and movement. Exp. Brain Res. 37:265-281.

Di Fabio, R. P. 1983. Postural supporting mechanisms during spontaneous single movement in the cat. Neurosci. Lett. 40:133-138.

Dufossé, M., J. Macpherson, and J. Massion. 1982. Biomechanical and electromyographical comparison of two supporting mechanisms in the cat. Exp. Brain Res. 45:38-44.

Flower, F., and D. M. Weary. 2006. Effect of hoof pathologies on subjective assessments of dairy cow gait. J. Dairy Sci. 89:139-146.
Gahéry, Y., and A. Nieoullon. 1978. Postural and kinetic coordination following cortical stimuli which induce flexion movements in the cat's limbs. Brain Res. 149:25-37.

Garbarino, E. J., J. A. Hernandez, J. K. Shearer, C. A. Risco, and W. W. Thatcher. 2004. Effect of lameness on ovarian activity in postpartum Holstein cows. J. Dairy Sci. 87:4123-4131.

Green, L. E., V. J. Hedges, Y. H. Schukken, R. W. Blowey, and A. J. Packington. 2002. The impact of clinical lameness on the milk yield of dairy cows. J. Dairy Sci. 85:2250-2256.

Greenough, P. R., and J. J. Vermunt. 1991. Evaluation of subclinical laminitis in a dairy herd and observations on associated nutritional and management factors. Vet. Rec. 128:11-17.

Hernandez, J., J. K. Shearer, and D. W. Webb. 2002. Effect of lameness on milk yield in dairy cows. J. Am. Vet. Med. Assoc. 220:640-644.

Hood, D. M., P. Wagner, D. D. Taylor, G. W. Brumbaugh, and M. K. Chaffin. 2001. Voluntary limb-load distribution in horse with acute and chronic laminitis. Am. J. Vet. Res. 62:1393-1398.

Jevens, D. J., C. E. DeCamp, J. G. Hauptman, T. D. Braden, M. Richter, and R. Robinson. 1996. Use of force-plate analysis of gait to compare two surgical techniques for treatment of cranial cruciate ligament rupture in dogs. Am. J. Vet. Res. 57:389-393.

Keegan, K. G., D. A. Wilson, D. J. Wilson, B. Smith, E. M. Gaughan, R. S. Pleasant, J. D. Lillich, J. Kramer, R. D. Howard, C. BaconMiller, E. G. Davis, K. A. May, H. S. Cheramie, W. L. Valentino, and P. D. van Harreveld. 1998. Evaluation of mild lameness in horses trotting on a treadmill by clinicians and interns or residents and correlation of their assessments with kinematic gait analysis. Am. J. Vet. Res. 59:1370-1377.

Manske, T., J. Hultgren, and C. Bergsten. 2002. Prevalence and interrelationships of hoof lesions and lameness in Swedish dairy cows. Prev. Vet. Med. 54:247-263.

Manson, F. J., and J. D. Leaver. 1988. The influence of concentrate amount on locomotion and clinical lameness in dairy cattle. Anim. Prod. 47:185-190.

Neveux, S., J. Oostra, A. M. de Passille, and J. Rushen. 2003. Validating on-farm tools for their ability to detect lameness in dairy cows. Page 129 in Proc. 37th Int. Congr. ISAE, Abano Terme, Italy. International Society for Applied Ethology, Brescia, Italy.

Neveux, S., A. M. de Passillé, J. Rushen, and D. Weary. 2004. Changes in weight distribution to detect hoof pain in dairy cows. Page 138 in Proc. 38th Int. Congr. ISAE, Helsinki, Finland. International Society for Applied Ethology, Brescia, Italy.

Nordlund, K. V., N. B. Cook, and G. R. Oetzel. 2004. Investigation strategies for laminitis problem herds. J. Dairy Sci. 87 (E. Suppl.):E27-E35.

Phillips, C. 2002. Locomotion and movement. Pages 180-297 in Cattle Behaviour and Welfare. 2nd ed. Blackwell, Univ. Cambridge, UK.

Rajkondawar, P. G., U. Tasch, A. M. Lefcourt, B. Erez, R. M. Dyer, and M. A. Varner. 2002. A system for identifying lameness in dairy cattle. Appl. Eng. Agric. 18:87-96.

Rietmann, T. R., M. Stauffacher, P. Bernasconi, J. A. Auer, and M. A. Weishaupt. 2004. The association between heart rate, heart rate variability, endocrine and behavioural pain measures in horses suffering from laminitis. J. Vet. Med. 51:218-225.

SAS Institute. 1985. SAS User's Guide: Statistics. Version 5. SAS Institute, Inc., Cary, NC.

Sprecher, D. J., D. E. Hostetler, and J. B. Kaneene. 1997. Lameness scoring system that uses posture and gait to predict dairy cattle reproductive performance. Theriogenology 47:1179-1187.

Wells, S. J., A. M. Trent, W. E. Marsh, and R. A. Robinson. 1993. Prevalence and severity of lameness in lactating dairy cows in a sample of Minnesota and Wisconsin herds. J. Am. Vet. Med. Assoc. 202:78-82.

Whay, H. R., D. C. J. Main, L. E. Green, and A. J. F. Webster. 2003. Assessment of the welfare of dairy cattle using animal-based measurements: Direct observations and investigation of farm records. Vet. Rec. 153:197-202.

Winckler, C., and S. Willen. 2001. The reliability and repeatability of a lameness scoring system for use as an indicator of welfare in dairy cattle. Acta Agric. Scand. A Anim. Sci. 30 (Suppl.):103-107. 